Check for updates

Cite this: RSC Adv., 2019, 9, 39447

\title{
Hexachlorobenzene exerts genotoxic effects in a humpback whale cell line under stable exposure conditions $\uparrow$
}

\begin{abstract}
Jenny Maner, (ID $\dot{t}^{\text {ab }}$ Michael Burkard, (iD $\dot{t}^{\text {ac }}$ Juan Carlos Cassano, ${ }^{d}$

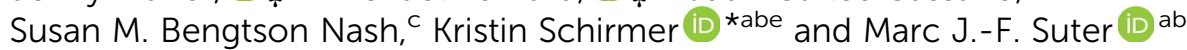

Humpback whales, like other polar wildlife, accumulate persistent organic pollutants. In Southern hemisphere populations, hexachlorobenzene $(\mathrm{HCB})$ dominates the contaminant profiles. $\mathrm{HCB}$ is linked to a variety of health effects and is classified as a group $2 \mathrm{~B}$ carcinogen, but the mechanism of action is a matter of contention. Potential toxicological effects to humpback whales remain entirely unknown. The recently established humpback whale fibroblast cell line (HuWa) offers an in vitro model for toxicological investigations. We here combine this novel cell line with a passive dosing strategy to investigate whale-specific toxicity of $\mathrm{HCB}$. The relevant partitioning coefficients were determined to produce stable and predictable exposure concentrations in small-scale bioassays. The system was used to assess acute toxicity as well as genotoxicity of HCB to the HuWa cell line. While we found some transient reductions in metabolic activity, measured with the indicator dye alamarBlue, no clear acute toxic effects were discernible. Yet, a significant increase in DNA damage, detected in the alkaline comet assay, was found in HuWa cells exposed to $10 \mu \mathrm{g} \mathrm{L}^{-1} \mathrm{HCB}$ during the sensitive phase of cell attachment. Collectively, this work provides a ready-to-use passive dosing system and delivers evidence that HCB elicits genotoxicity in humpback whale cells.
\end{abstract}

Received 12th July 2019

Accepted 15th November 2019

DOI: $10.1039 / c 9 r a 05352 b$

rsc.li/rsc-advances

\section{Introduction}

Persistent organic pollutants (POPs) deposited in polar regions have been found to bioaccumulate in polar wildlife. ${ }^{1,2}$ In the Southern hemisphere, hexachlorobenzene (HCB) dominates contaminant profiles, ${ }^{3-7}$ including those of humpback whales (Megaptera novaeangliae) feeding in Antarctica. ${ }^{8-10}$

HCB exhibits typical legacy POP characteristics such as high stability ( $>6$ years half-life in biota), hydrophobicity $\left(\log K_{\text {ow }}=5.73 \text {, max. water solubility }=5 \mu \mathrm{g} \mathrm{L}^{-1}\right)^{11,12}$ and volatility $\left(H=35 \mathrm{~Pa} \mathrm{~m}^{3} \mathrm{~mol}^{-1}\right) \cdot{ }^{13,14}$ In humans and mice, $\mathrm{HCB}$ exposure is associated with low acute toxicity, but chronic exposure has been linked to a variety of health effects,

${ }^{a}$ Department Environmental Toxicology, Eawag, Swiss Federal Institute of Aquatic Science and Technology, 8600 Dübendorf, Switzerland. E-mail: kristin.schirmer@ eawag.ch

${ }^{b}$ Department of Environmental Systems Science, ETH Zürich, 8092 Zürich, Switzerland ${ }^{c}$ Southern Ocean Persistent Organic Pollutants Program, Environmental Futures Research Institute, Griffith University, Brisbane, QLD 4108, Australia

${ }^{d}$ Empa, Swiss Laboratories for Material Science and Technology, Particle-Biology Interactions Laboratory, 9014 St Gallen, Switzerland

${ }^{e}$ School of Architecture, Civil and Environmental Engineering, EPF Lausanne, 1015 Lausanne, Switzerland

$\dagger$ Electronic supplementary information (ESI) available. See DOI: 10.1039/c9ra05352b

$\ddagger$ These authors contributed equally to this work. including immunotoxicity, reproductive and developmental toxicity, neurobehavioral impairment, endocrine disruption, hepatic toxicity, kidney damage and cardiotoxicity. ${ }^{15,16}$ The international agency for research on cancer classified HCB as a group 2B carcinogen interfering with the liver, ovary and the central nervous system. ${ }^{17}$ However, whether HCB is genotoxic is a matter of debate in the literature.

Dramatic weight loss has been found to result in the remobilisation of HCB from adipose tissue into the blood stream, and subsequent redistribution to other tissues in mice. ${ }^{18}$ This may be particularly problematic for humpback whales due to their unique life history traits, involving migration between feeding and breeding grounds, associated with extended periods of fasting and depletion of fat reserves. ${ }^{8,19}$ To date, however, nothing is known about the species-specific toxicity of HCB to baleen whales. Controlled experimentation on large, free-roaming cetaceans is neither logistically nor ethically feasible, hence novel effect assessment tools have been repeatedly sought by researchers and environmental agencies alike. ${ }^{20,21}$

Cell lines can be a powerful method to study mechanisms of toxicity and potential species differences. ${ }^{22}$ Cell lines have been established and successfully applied in toxicity testing for several cetaceans, including a number of Mediterranean dolphin species and Arctic beluga whales. ${ }^{23,24}$ Recently, we developed a humpback whale fibroblast cell line (HuWa), for the first time opening up the possibility for in vitro effect 
assessment for this species. ${ }^{25}$ First toxicological investigations using this cell line highlighted human-whale interspecies differences in sensitivity to typical POP compounds accumulating in the blubber of humpback whales, underscoring the need for species-specific risk assessment. ${ }^{25}$ HuWa cells have moreover been transfected by exogenous gene transfer with telomerase reverse transcriptase (TERT), which enables longterm preservation of HuWa cell lines. ${ }^{26}$

While the establishment of the HuWa cell line offers novel opportunities for exploring the toxicity of chemicals to humpback whales, HCB's physico-chemical properties comprise a challenge, especially in small-scale cell bioassay systems, which favour sorption of hydrophobic chemicals and are prone to losses through volatilisation. Most effect evaluation studies to date have been conducted by dissolving $\mathrm{HCB}$ in an organic solvent. ${ }^{27-30}$ However, stable exposure concentrations cannot be reached in this way. ${ }^{31-33}$ It was, for example, shown that concentrations of a PAH and a chlorobenzene decrease dramatically over time in a solvent-spiked setup: concentrations of benzo( $a$ )pyrene and $1,2,4$-trichlorobenzene were reduced to $64 \%$ and $11 \%$ of the original concentrations, respectively, 48 hours after direct spiking. ${ }^{33}$ As a consequence, effect concentrations derived from nominal concentrations may grossly underestimate toxicity. ${ }^{33}$

One approach to achieve well-defined exposure conditions is silicone-based passive dosing. Silicone is chemically inert, biologically compatible, and features high absorption capacities for hydrophobic chemicals; it can thus be 'loaded' with hydrophobic chemicals and act as a reservoir. Based on the concentration gradient between the reservoir and the other compartments in the system, the chemical diffuses into the exposure medium where a stable concentration is achieved at the equilibrium level. Thus, losses in the exposure system can be compensated and the need for co-solvents eliminated. Both silicone discs, rods, and O-rings have been used in different toxicity assays and with various classes of organic chemicals, including chlorobenzenes. ${ }^{33-41}$

In the present study, a ready-to-use passive dosing setup for HCB was established and all the necessary partitioning coefficients were determined. Silicon O-rings were used as a reservoir to achieve stable and predictable HCB concentrations in mammalian cell culture medium. The setup was employed to carry out in vitro cytotoxicity and genotoxicity tests with the novel HuWa $\mathrm{TERT}_{\text {TER }}$ cell line. This is the first study focussing on species-specific toxicity tests for humpback whales with HCB.

\section{Materials and methods}

\subsection{Chemicals and materials}

All chemicals and solvents were purchased from Sigma-Aldrich (Buchs, Switzerland), except ${ }^{13} \mathrm{C}_{6}$-hexachlorobenzene (nonane, $100 \mu \mathrm{g} \mathrm{mL}^{-1}$ ), which was purchased from Cambridge Isotope Laboratories (Cambridge, UK). Cell culture consumables were purchased from Life Technologies Invitrogen (Basel, Switzerland), except trypsin, which was purchased from Biowest (Nuaill, France), and fetal bovine serum (FBS), which was purchased from Eurobio (Courtaboeuf, France). Cell culture flasks were purchased from TPP (Trasadingen, Switzerland) and cell culture plates from Greiner bio-one (Frickenhausen, Germany). Autosampler vials and crimp caps with silicone/ polytetrafluoroethylene (PTFE) septa were purchased from BGB Analytik AG (Böckten, Switzerland), while amber glass vials with PTFE-lined melamine resin screw were purchased from Sigma-Aldrich (Buchs, Switzerland). GERSTEL Twisters® were purchased from GERSTEL GmbH \& Co. KG (Mülheim an der Ruhr, Germany), and silicone O-rings (9.92 $\mathrm{mm} \times 2.62 \mathrm{~mm}$ ) were purchased from Hutchinson Suisse (Langnau am Albis, Switzerland). The OxiSelect Comet Assay Kit was purchased from Cell Biolabs, Inc. (San Diego, CA, USA).

\subsection{Loading of O-rings with $\mathrm{HCB}$ and determination of the partitioning coefficient $K_{\mathrm{LB} \text { :sil }}$}

All equations relating to the establishment of the passive dosing setup are given in Table S1. $\dagger$ O-rings with an inner and outer diameter of 9.92 and $15.16 \mathrm{~mm}$, respectively, a mass of $258 \pm$ $3 \mathrm{mg}(n=75)$ (Fig. $\mathrm{S} 1 \dagger)$, and a calculated volume of $0.212 \mathrm{~mL}$ were used as passive dosing reservoirs. O-rings were pre-cleaned by Soxhlet extraction using cyclohexane and methanol. Clean $\mathrm{O}-$ rings were stored in deionised nanopure $\mathrm{H}_{2} \mathrm{O}\left(\mathrm{dH}_{2} \mathrm{O}\right)$ at room temperature until use.

HCB was loaded onto O-rings by partitioning loading as previously described. ${ }^{33}$ Briefly, a stock solution of HCB in methanol (100 $\mu \mathrm{g} \mathrm{mL} \mathrm{m}^{-1}$, Sigma-Aldrich) was diluted to the desired concentration in a loading buffer (LB) of $\mathrm{HCB}$ in methanol/ $\mathrm{H}_{2} \mathrm{O} 60: 40$ (v/ $\mathrm{v})$ at a volume of $2 \mathrm{~mL}$ per O-ring, and the clean O-rings were equilibrated in this LB in amber glass vials (room temperature, shaking at $250 \mathrm{rpm}$ on a benchtop orbital shaker (IKA KS125)). Push loading, a variant of partitioning loading, whereby the proportion of water in the LB is steadily increased, thereby "pushing" the HCB into the silicone, was also tested in the current study, but was found to be less efficient (see ESI Section 1.c. and Table S2 $\dagger$ ), and was therefore not further used.

The partitioning coefficient between LB and silicone ( $\left.K_{\mathrm{LB}: \mathrm{sil}}\right)$ is defined by the concentrations of HCB in the two phases at equilibrium. In order to determine $K_{\mathrm{LB} \text { :sil }}$, various starting concentrations of $\mathrm{HCB}$ in $\mathrm{LB}$ were used and the resulting equilibrium concentrations in LB and in silicone analysed. $K_{\mathrm{LB}: s i l}$ could then be used to predict concentrations on O-rings based on the starting concentration of $\mathrm{HCB}$ in $\mathrm{LB}$, or conversely to determine the necessary LB starting concentration to achieve a specified concentration on O-rings.

To identify the maximal loading capacity of silicone, a suspension of solid $\mathrm{HCB}$ in methanol $/ \mathrm{H}_{2} \mathrm{O}$ (saturation loading) was used as LB as previously described..$^{34,35,38}$ For this, the HCB suspension was sonicated for one hour at $4{ }^{\circ} \mathrm{C}$ to enhance dissolution and the LB was equilibrated for 1 week. In this setup, suspended HCB crystals served as reservoir to maintain the saturation level in the LB by dissolution, while $\mathrm{O}$ rings were saturated by partitioning from the LB.

\subsection{Passive dosing and determination of the partitioning coefficients $K_{\text {sil:DMEM/F12 }}$}

Size and density of the O-rings were selected to fit into the wells of a 24-well plate; they float at the surface of the aqueous 
medium due to the surface tension. Passive dosing was carried out under sterile conditions. For this, loaded O-rings were rinsed first with methanol and then sterile $\mathrm{dH}_{2} \mathrm{O}$, dabbed dry and placed into $20 \mathrm{~mL}$ amber vials to equilibrate in Dulbecco's Modified Eagle Medium (DMEM)/F12 (2 mL per O-ring, $37{ }^{\circ} \mathrm{C}$, $250 \mathrm{rpm})$. Partitioning coefficients between silicone and DMEM/F12 $\left(K_{\text {sil:DMEM/F12 }}\right)$ were calculated from the concentration of HCB in silicone and the equilibrium concentration of HCB in DMEM/F12 for both serum-free (0\% FBS) and serumcontaining (1\% FBS) medium.

\subsection{Chemical analysis}

For quantification of HCB in silicone, each O-ring was extracted by solid-liquid extraction using $10 \mathrm{~mL}$ cyclohexane and incubation for 72 hours at $300 \mathrm{rpm}$ in $20 \mathrm{~mL}$ amber glass vials. Samples of the LB $(1.5 \mathrm{~mL})$ were extracted twice by liquid-liquid extraction with $750 \mu \mathrm{L}$ cyclohexane and the extracts were combined. Medium samples were extracted by liquid-solid extraction using PDMScoated magnetic stir bars (GERSTEL Twisters ${ }^{\circledR}$ ), which were subsequently extracted three times overnight with $500 \mu \mathrm{L}$ cyclohexane after which the extracts were combined. ${ }^{13} \mathrm{C}_{6}$-marked $\mathrm{HCB}$ was added as internal standard to all loading buffer and medium samples prior to extraction (nominal final concentration in extract $100 \mu \mathrm{g} \mathrm{L}^{-1}$ ) and the extracts were then concentrated to a volume of $100 \mu \mathrm{L}$ using laminar nitrogen flow. Samples were transferred to glass inserts $(100 \mu \mathrm{L})$ in autosampler vials $(2 \mathrm{~mL})$. All aliquots were analysed using a gas chromatograph coupled to a mass spectrometer (Trace GC Ultra/ITQ900, Thermo Scientific). Mass $m / z 284$ $([\mathrm{M}+2]$ isotope) was monitored for the analyte, while mass $m / z 294$ $[\mathrm{M}+6]$ was monitored for the ${ }^{13} \mathrm{C}_{6}$-labelled internal standard in order to minimise isotope contribution from the unlabelled analyte $(0.36 \%$ contribution). For quantification, the chromatographic peak area of $\mathrm{m} / \mathrm{z} 284$ was divided by the chromatographic peak area of $m / z 294$, using 20, 50, 100, 200, 500, 1000, 2000, 5000, $10000 \mu \mathrm{g}$ $\mathrm{L}^{-1} \mathrm{HCB}$ for the calibration curve. For O-ring extracts, pure cyclohexane was used as blank, while for loading buffer and medium samples a methanol-water mixture $(60: 40)$ was spiked with ${ }^{13} \mathrm{C}_{6}$-marked HCB and extracted in the same manner as the samples. The LOD was $5 \mu \mathrm{g} \mathrm{L}^{-1}$ (signal/noise $\geq 2$ ), and the LOQ 10 $\mu \mathrm{g} \mathrm{L}^{-1}$ (signal/noise $\geq 10$ ).

\subsection{Cell culture and exposure setup}

In vitro toxicity testing was performed using TERT-transfected cells of the HuWa cell line of humpback whale fibroblasts (HuWa ${ }_{\text {TERT }}$, passages $\left.16-36\right),{ }^{26}$ a cell line established in this research group. Cells were handled under sterile conditions, and all materials used were autoclaved. Cell lines were cultured in DMEM/F12 medium, containing 10\% FBS, $0.1 \mathrm{M}$ nonessential amino acids, $1 \mathrm{M}$ sodium pyruvate and $1 \%$ penicillin-streptomycin $\left(5.000 \mathrm{U} \mathrm{mL}^{-1}\right)$. Cultures were maintained in $75 \mathrm{~cm}^{2}$ cell culture flasks at $37{ }^{\circ} \mathrm{C}$ and $5 \% \mathrm{CO}_{2}$. The medium was changed twice a week and at $80-90 \%$ confluency, cells were trypsinised, centrifuged $(600 \times g, 3 \mathrm{~min}$, room temperature) and passaged at a ratio of $1: 3$.

For toxicity testing, HuWa $\mathrm{a}_{\text {TERT }}$ were either exposed to HCB in a confluent monolayer or during the phase of suspension and attachment to well bottoms. For exposure of cells in confluent monolayer, cells were trypsinised, centrifuged, seeded into the wells of 24 well plates at a density of $1.7 \times 10^{4}$ cells per $\mathrm{cm}^{2}$, and allowed to attach and form confluent monolayers for 48 hours. Exposure medium containing 1\% FBS was used in order to allow cells to maintain their normal function while minimising interference of FBS constituents with HCB. The exposure medium was pre-equilibrated with HCB by placing loaded O-rings in $2 \mathrm{~mL}$ DMEM/F12 per ring for 20 hours in $20 \mathrm{~mL}$ amber glass vials $\left(37{ }^{\circ} \mathrm{C}, 250 \mathrm{rpm}\right)$. Then, HCB-loaded O-rings were removed from medium, rinsed with $70 \%$ ethanol and sterile $\mathrm{dH}_{2} \mathrm{O}$, and air-dried for $30 \mathrm{~min}$, to remove any medium components which may impede the O-rings' staying afloat in the well plates. The culture medium from the wells containing the cell monolayers was exchanged with $700 \mu \mathrm{L}$ per well of the HCB-preequilibrated DMEM/F12 culture medium, and one O-ring per well was carefully placed afloat with sterile metal tweezers. For the negative controls, O-rings were 'loaded' in methanol $/ \mathrm{H}_{2} \mathrm{O}$ solution without $\mathrm{HCB}$, and control medium was pre-equilibrated with these blank O-rings. The control medium was then added to wells of cells used as unexposed controls with the blank O-rings placed afloat. Pre-experiments confirmed that the O-rings by themselves did not impact $\mathrm{HUWa}_{\text {TERT }}$ cell viability; thus, controls without O-rings were subsequently omitted from all tests. Plates were covered with aluminium foil, sealed and incubated under gentle agitation of $30 \mathrm{rpm}$ at $37{ }^{\circ} \mathrm{C}$ or, in case of the temperature stress experiment, $30^{\circ} \mathrm{C}$, for up to 24 hours.

For exposure from suspension to attachment, $1.5 \times 10^{4}$ cells per $\mathrm{cm}^{2}$ were seeded in $700 \mu \mathrm{L}$ of pre-equilibrated DMEM/F12 in 24 well plates, or, for genotoxicity testing, in $1.4 \mathrm{~mL}$ preequilibrated DMEM/F12 in 12-well plates. One O-ring per well was placed afloat, plates covered with aluminium foil, sealed, and incubated at $37^{\circ} \mathrm{C}$ and $30 \mathrm{rpm}$, for up to 24 hours.

\subsection{HCB exposure concentrations}

Measured blubber concentrations of HCB in a population of Southern hemisphere humpback whales have been found to range from an average of $\sim 60 \mathrm{ng} \mathrm{g}_{\text {lipid }}{ }^{-1}$ post-summer feeding to an average of $\sim 200 \mathrm{ng}$ glipid $^{-1}$ about halfway into their seasonal migration. ${ }^{8}$ No values of blood plasma concentrations of HCB in humpback whales are available; however, a rough estimation may be done based on either the partitioning coefficients for HCB between blubber and plasma derived for bottlenose dolphins, ${ }^{42}$ or a physiologically-based pharmacokinetic model of HCB distribution in a humpback whale. ${ }^{43}$ Both approaches yield very similar results of HCB blood plasma concentrations ranging from $\sim 0.3$ to $1.0 \mu \mathrm{g}$ $\mathrm{L}_{\text {plasma }}{ }^{-1}$ from the beginning to the middle of the fasting period (see ESI Section 1.e. for details $\dagger$ ). Hence, to assess the impact of HCB at environmentally relevant as well as elevated concentrations representative of potential peak exposure towards the end of migration, HCB exposure concentrations of 1, 5, and $10 \mu \mathrm{g} \mathrm{L}^{-1} \mathrm{HCB}$ were chosen, assuming that blood plasma concentrations approximately equate exposure concentrations to cells in vivo. 


\subsection{Cytotoxicity testing}

Toxicity was evaluated by measuring cell metabolic activity and membrane integrity by means of the fluorescent indicator dyes alamarBlue (AB) and 5-carboxyfluorescein diacetate acetoxymethylester (CFDA-AM), respectively, as previously described. ${ }^{44} \mathrm{AB}$ is based on the cell-permeable, non-fluorescent dye resazurin, which is transformed by mitochondrial, microsomal, or cytoplasmic oxidoreductases to the highly fluorescent resorufin, ${ }^{45}$ serving as an indicator for cellular metabolism of viable cells. ${ }^{46}$ CFDA-AM is a non-polar molecule which diffuses into cells, where it is converted into the polar, fluorescent dye, 5 -carboxyfluorescein, ${ }^{47}$ by intracellular esterases. An intact plasma membrane will retain the polar product and thus yield higher fluorescent intensity. Briefly, after exposure for three, six, and 24 hours, the medium was discarded, cells were washed once with phosphate-buffered saline (PBS) and incubated for 25 min with $5 \%(\mathrm{v} / \mathrm{v}) \mathrm{AB}$ and $1 \%(\mathrm{v} / \mathrm{v})$ CFDA-AM in PBS at $37{ }^{\circ} \mathrm{C}$. Fluorescence was measured at excitation/emission wavelengths of 530/595 nm and 493/541 nm for $\mathrm{AB}$ and CFDA-AM, respectively. The results were expressed as percentage of the unexposed control, which was set to $100 \%$.

\subsection{Genotoxicity testing}

DNA damage was measured by the alkaline comet assay, also called single-cell gel electrophoresis, which detects both singleand double-strand breaks, as well as DNA adducts. ${ }^{48}$ The principle of this assay is that smaller fractions of DNA migrate faster through agarose gels during electrophoresis. For this purpose, cells are lysed and DNA is denatured prior to a micro-gel electrophoresis. While undamaged DNA migrates in bulk, damaged DNA (single- and double strand breaks) exhibits a characteristic tailing, termed comet, which can be identified visually by DNA staining.

Based on the cell viability tests, HuWa $\mathrm{T}_{\text {TERT }}$ cells were more sensitive to HCB during the transition from suspension to attachment (which takes about three hours) compared to established cell monolayers (which takes about 24 hours). Therefore, we decided to assess DNA damage occurring within this sensitive window of suspension to attachment, i.e. after three hours of HCB exposure. The comet assay was performed using the OxiSelect Comet Assay Kit (Cell Biolabs, Inc., San Diego, CA, USA) according to the provided protocol with minor modifications. Briefly, after three hours of HCB exposure during the attachment phase, cells were washed with icecold PBS (without $\mathrm{Mg}^{2+} / \mathrm{Ca}^{2+}$ ), trypsinised, and centrifuged. The pellet was washed with ice-cold PBS (without $\mathrm{Mg}^{2+} / \mathrm{Ca}^{2+}$ ) and centrifuged again. Cells were then re-suspended in icecold PBS (without $\mathrm{Mg}^{2+} / \mathrm{Ca}^{2+}$ ) at $1 \times 10^{5}$ cells per $\mathrm{mL}$, mixed with preheated agarose $\left(37^{\circ} \mathrm{C}\right)$ in a ratio of $1: 10(\mathrm{v} / \mathrm{v})$, and pipetted onto the provided comet slides (75 $\mu \mathrm{L}$ per well). Control and HCB-treated cells were placed in different wells on the same slide. Slides were incubated for 15 minutes at $4{ }^{\circ} \mathrm{C}$ in the dark, and subsequently immersed in lysis buffer and incubated overnight at $4{ }^{\circ} \mathrm{C}$ in the dark. Next, slides were incubated in alkaline solution for 30 minutes at $4{ }^{\circ} \mathrm{C}$ in the dark. Thereafter, electrophoresis was performed in alkaline electrophoresis solution in a small chamber $(15 \mathrm{~cm}$ diameter, Bio-Rad Laboratories, Inc., Hercules, CA, USA) at $20 \mathrm{~V}(\sim 300$ $\mathrm{mA}$ ) for 30 minutes. Following electrophoresis, slides were washed twice with $\mathrm{dH}_{2} \mathrm{O}$ and once with ethanol and left to dry. Finally, cells were stained with Vista Green DNA dye and analysed by fluorescence microscopy (Leica DMI 6000B, Leica Microsystems, Wetzlar, Germany) at excitation/emission wavelengths of 494/521 $\mathrm{nm}$.

\subsection{Data evaluation}

With regard to the passive dosing set-up, linear regression and the coefficient of determination $\left(R^{2}\right)$ were assessed between HCB concentrations in loading buffer and resulting HCB concentrations in silicone, as well as between HCB concentrations in silicone, and resulting HCB concentrations in DMEM/ F12. Time to equilibrium was determined by fitting a onecompartment model using MATLAB. The partitioning coefficients were calculated according to the formulae given in Table S1.† Unless otherwise stated, shown data represent the mean of three technical replicates measured in a single experiment, and error bars represent the standard deviation (SD).

In case of cell-based experiments, data represent the mean of at least three biological replicates and error bars indicate the 95\% confidence interval (CI). Statistical difference was assessed for metabolic activity and membrane integrity of cells exposed to HCB in monolayer or suspension at different time-points. For this, cell viability was compared between HCB concentrations $\left(1,5\right.$, and $\left.10 \mu \mathrm{g} \mathrm{L}^{-1}\right)$ and the unexposed control. Data were logtransformed and analysed by one-way ANOVA with Dunnett's post hoc test, and by two-tailed unpaired $t$-test in case of the temperature-stress experiments, for which only $10 \mu \mathrm{g} \mathrm{L}{ }^{-1} \mathrm{HCB}$ concentration was tested. Any value for $p<0.05$ was considered significant and marked with an asterisk. The analysis was done using GraphPad Prism Version 5 (La Jolla, CA, USA).

Comet assay images were analysed with Comet Assay IV software (Perceptive Instruments, Bury St Edmunds, UK). Tail intensity was chosen as descriptor and a total of 100 cells each for HCB-treated and control samples were analysed. While the data generated in the comet assay are never normally distributed, the mean of several replicate comet assays will be approximately normally distributed. ${ }^{49}$ Thus, mean tail intensities of cells exposed to $10 \mu \mathrm{g} \mathrm{L^{-1 }} \mathrm{HCB}$ and the unexposed controls were compared by means of a two-tailed unpaired $t$-test from four biological replicates. Any value for $p<0.05$ was considered as significant and marked with an asterisk. The comet assay performed with all three HCB concentrations (1, 5, and $10 \mu \mathrm{g} \mathrm{L}^{-1}$ ) is based on technical replicates (one biological replicate) and thus no statistical analysis was performed.

\section{Results and discussion}

\subsection{Characterisation of the passive dosing setup for HCB}

Silicone O-rings were chosen as passive dosing reservoir because they are commercially available in various standardised sizes, ${ }^{34}$ which is important to minimize variance in exposure concentration. They were loaded with HCB by partitioning 
loading, whereby the chemical partitions from a methanolbased LB into silicone by diffusion until equilibrium between the two phases is reached. ${ }^{3-35,38}$ Hydrophobic chemicals preferentially partition from this polar solution into the silicone. Excess LB can be washed off with water to avoid contact of the solvent or crystallised chemical with the cells. ${ }^{35}$ In this study, a loading efficiency of $84 \pm 10 \%$ was achieved using an LB of methanol/water $60: 40 \%(\mathrm{v} / \mathrm{v})$. In contrast, a loading efficiency of only $\sim 70 \%$ was achieved in a study where hexane was used as LB and evaporated off to force absorption of HCB into the reservoir. ${ }^{50}$ Equilibrium distribution of HCB between LB and silicone was reached within six hours (Fig. 1a, top) and remained stable for at least five days (Fig. S2 $\dagger$ ). HCB equilibrium was established from different concentrations in the LB, with a linear relationship between HCB concentrations in LB and on O-rings at equilibrium (Fig. 1a, bottom). The saturation concentration of HCB in silicone was $\sim 610 \mathrm{mg} \mathrm{L}^{-1}$.

Loaded O-rings placed into DMEM/F12 exposure medium revealed rapid release of $\mathrm{HCB}$ in the first hours of preequilibration. Equilibrium was established within nine hours and remained constant for at least 54 hours in closed glass vials with submerged O-rings (Fig. 1b, top). Release kinetics in serum-free DMEM/F12 were similar (Fig. S3†), but as the standard setup was with $1 \%$ FBS, time until equilibrium was determined only for medium with FBS. HCB concentration in exposure medium showed a linear relationship with HCB concentration in the silicone O-ring (Fig. 1b, bottom). While HCB solubility in water is only $5 \mu \mathrm{g} \mathrm{L^{-1 } , 1 2}$ concentrations in serum-free DMEM/F12 of up to $25 \mu \mathrm{g} \mathrm{L}^{-1}$ have been achieved in this study using passive dosing. In DMEM/F12 with 1\% FBS, approximately four times higher HCB concentrations were reached compared with serum-free DMEM/F12 (Fig. 1b, bottom).

Upon transfer of the pre-equilibrated DMEM/F12 into 24well-plates containing confluent monolayers of $\mathrm{HuWa}_{\mathrm{TERT}}$ cells, covered with aluminium foil, a new equilibrium established itself within 6 hours, and HCB concentration remained constant for at least 96 hours (Fig. 1c). The same was true if plates were covered with adhesive plastic foil, but due to the plastic foil acting as an additional sink for $\mathrm{HCB}$, a new equilibrium concentration in DMEM/F12 established itself at a slightly lower concentration (Fig. $\mathrm{S} 4 \dagger$ ).

The partitioning coefficients for distribution of HCB between LB, silicone, and DMEM/F12 were calculated based on the equilibrium concentration of $\mathrm{HCB}\left(\left[\mu \mathrm{g} \mathrm{L}{ }^{-1}\right]\right)$ in these phases (Fig. 1d). For comparison purposes, partitioning coefficients based on the HCB concentration in silicone, defined by mass of silicone $\left(\left[\mu \mathrm{g} \mathrm{kg}{ }^{-1}\right]\right)$, were also calculated, with only slight variations in the resulting values (Table S3 $\dagger$ ). The determined HCB partitioning coefficient between silicone and serum-free a) Silicone O-ring loading
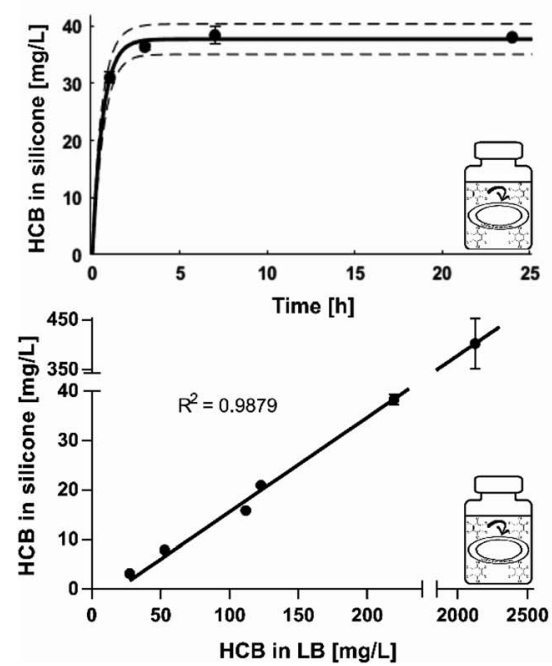

b) Medium pre-equilibration
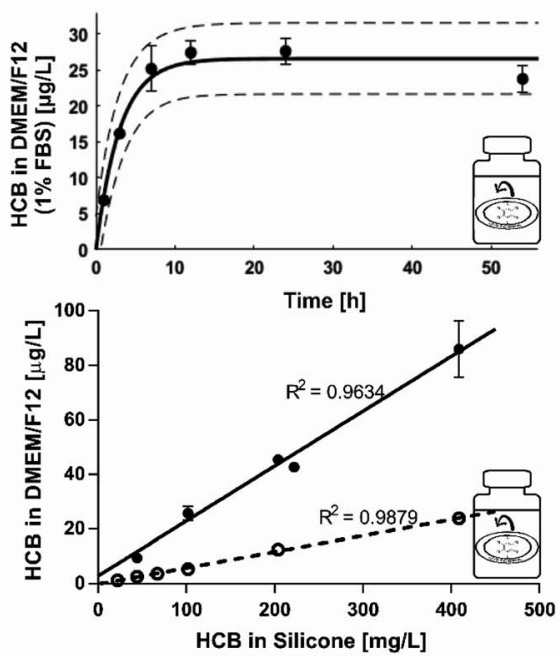

c) Exposure of HuWa $\mathrm{T}_{\mathrm{TERT}}$ cells

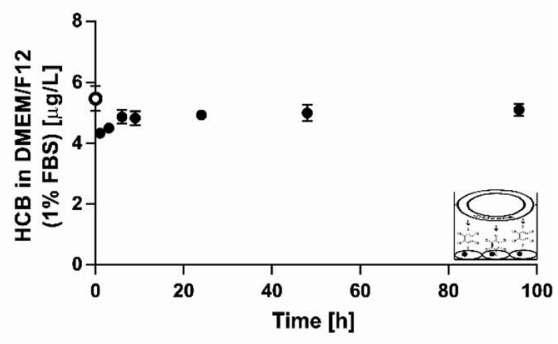

d) Partitioning coefficients

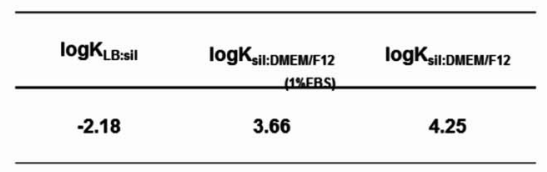

Fig. 1 Characterisation of the HCB passive dosing setup. (a) Loading of silicone O-rings. Top: time to steady-state by equilibrium partitioning from a loading buffer of methanol/water $60: 40(\mathrm{v} / \mathrm{v})$ at room temperature and $250 \mathrm{rpm}$. Points represent the mean of three technical replicates (i.e. three independently prepared O-rings), error bars represent the standard deviation (SD). Bottom: resulting concentrations of $\mathrm{HCB}$ in silicone established from varying concentrations of HCB in LB. Means of three to twelve technical replicates with SD (note the differential scaling of the upper and lower segments of the axes). (b) Pre-equilibration of DMEM/F12 exposure medium. Top: time to steady-state in DMEM/F12 (1\% FBS) with submerged HCB-loaded silicone O-rings in amber glass vials at $37{ }^{\circ} \mathrm{C}$ and $250 \mathrm{rpm}$. Means of three technical replicates with SD. Bottom: resulting concentrations of HCB in DMEM/F12 (solid symbols - : with 1\% FBS; open symbols $O$ : serum-free) established from varying concentrations of HCB in silicone. Means of three to six technical replicates with SD. (c) Concentration stability during exposure of cells. Concentration of HCB in exposure medium DMEM/F12 (1\% FBS) immediately after pre-equilibration (at 0 hours, open symbol $O$ ), and after transfer to a 24-well plate containing a confluent monolayer of cells $\left(1 \times 10^{4}\right.$ cells per $\mathrm{cm}^{2}$ seeded two days prior to exposure), with a loaded $\mathrm{O}$ ring placed afloat, covered with aluminium foil, sealed and incubated at $37^{\circ} \mathrm{C}$ and $30 \mathrm{rpm}$ (solid symbols $)$ ). Means of three technical replicates with SD. (d) Partitioning coefficients for HCB. Between LB and silicone (sil), and between sil and DMEM/F12. 
DMEM/F12 (0\% FBS), $\log K_{\text {sil:DMEM/F12( } 0 \% \text { FBS })}=4.25$, is slightly lower than the previously published partitioning coefficients for HCB between silicone and water (Table S4†), indicating that the medium components in DMEM/F12 (e.g. glucose, amino acids, salts and vitamins) influence the distribution of HCB slightly in favour of partitioning to the medium, even without the addition of FBS. The partitioning coefficient for HCB in medium with serum ( $1 \% \mathrm{FBS}), \log K_{\text {sil:DMEM/F12(1\% FBS) }}=3.66$, is in line with other findings for chemicals with similar physico-chemical properties (Table S5 $\dagger$ ). It is lower than the partitioning coefficient for serum-free medium, indicating that serum increases the solubility of HCB and thus drives its distribution into the medium. Serum constituents such as lipids and proteins are known to significantly bind certain chemicals; for example, bovine serum albumin is reported to bind chlorinated substances such as hexachlorobiphenyl. ${ }^{51}$

An experiment was performed to determine whether loaded Orings could be re-used for passive dosing. However, it was found that a slightly reduced loading concentration occurs with each usage cycle (Fig. S5 $\dagger$ ). Thus, new O-rings were loaded for each experiment in our study. However, it is conceivable to re-use the loaded O-rings in order to save starting materials and produce less toxic waste if the decrease in concentration in the silicone, and consequently in the dosed medium, is accounted for.

In summary, we found that equilibrium loading is an efficient method to load HCB onto O-rings, and concentrations in silicone rings can be well predicted from defined LB concentrations. Silicone O-rings present a large enough reservoir and suitable partitioning properties to allow the establishment of precise exposure concentrations for HCB over a wide concentration range, even above the presumed level of water solubility. The determined partitioning coefficients are in agreement with previously published values. Thus, the characterised passive dosing setup is a suitable and convenient method for toxicity testing with HCB.

\subsection{Toxicity of HCB to humpback whale fibroblasts}

3.2.1. Effect of HCB on cell viability. HCB did not have significant effects on metabolic activity and membrane integrity of cells in established monolayers within 24 hours of exposure, except for a transient reduction in metabolic activity (Fig. 2a). Cells exposed to HCB in suspension also showed a transient reduction in metabolic activity, the effect being measurable already after three hours and in all HCB concentrations (Fig. 2b). The cells attach to the well bottom and form cell-cell interactions in the first hours after seeding, thus cells may be more susceptible to $\mathrm{HCB}$ in this phase compared to their adherent state. It has previously been shown that mouse fibroblasts and sarcoma cells, which are usually grown in adherent cultures, react more sensitively to cytotoxicity tests in suspension. $^{52}$ However, the effect does not persist after 24 hours. The fact that the observed effect on metabolic activity is only transient suggests that it is not a result of cell death. Moreover, attachment efficiency cannot be compromised, since CFDA-AM fluorescence did not decrease in a similar manner. We can speculate that the reduced metabolic activity may be linked to a temporary redistribution of energy while cells adapt, or, in line with the observation of genetic damage (see Section 3.2.2. below), by the induction of DNA repair mechanisms.

Combinations of HCB with other stress factors did not reveal any clear trends: cells exposed to HCB in a confluent monolayer at a reduced temperature of $30{ }^{\circ} \mathrm{C}$ instead of the optimal $37^{\circ} \mathrm{C}$ showed slightly reduced metabolic activity after three and 24 hours, but not after six hours (Fig. S6†), while cells exposed to HCB in a confluent monolayer in medium without FBS showed no reduction in cell viability (Fig. $\mathrm{S} 7 \dagger$ ).

To our knowledge, no prior study has explored the impact of HCB on vertebrate cell viability under stable exposure conditions. However, other studies have assessed the impact of HCB on different vertebrate cells by means of solvent-mediated dosing. The findings vary for different cell types and concentration ranges, with some studies having dosed $\mathrm{HCB}$ at concentrations several orders of magnitude above its maximum water solubility. ${ }^{27,28}$ Resulting concentration instability may be one of the reasons for divergence in reported concentrationresponses as outlined below.

Mouse embryonic fibroblast cells (NIH 3T3), similarly to our own findings, showed a transient decrease in cell viability and a decrease in total cell number within 24 hours at concentrations of 0.1 and $1 \mu \mathrm{g} \mathrm{L}{ }^{-1} \mathrm{HCB}^{29}$ As cell-cycle progression was unaffected, the authors attributed the reduction in cell number to apoptosis. In the same study, human embryonic fibroblasts (WS1) exposed to $1 \mu \mathrm{g} \mathrm{\textrm {L } ^ { - 1 }}$ HCB also decreased in cell numbers but without any reduction of cell viability. In this case, cell-cycle arrest and reduced proliferation as a consequence of $\mathrm{HCB}$ exposure was held to be the cause of the reduced cell number. A study with rat thyroid cells (FRTL-5) found a significant reduction in cell viability after eight hours exposure to HCB concentrations of 142 and $1424 \mu \mathrm{g} \mathrm{L}^{-1}$, i.e. one to two orders of magnitude higher than what we used in our study, while, at the more comparable concentration ranges of 1.4 and $14 \mu \mathrm{g} \mathrm{L}^{-1}$, no effect was observed. ${ }^{28}$ In contrast, human colon adenocarcinoma cells (Caco-2), exposed to HCB in a confluent monolayer, showed a reduction of viability already at $0.01 \mu \mathrm{g} \mathrm{L}^{-1} \mathrm{HCB}$, i.e. one order of magnitude lower than our lowest concentration, with a dose-dependent increase in the observed effect up to the maximum tested concentration of $570 \mu \mathrm{g} \mathrm{\textrm {L } ^ { - 1 }}$, but this effect was only observed after 14 days of exposure. ${ }^{27}$

Membrane integrity in our study appeared to be unaffected by HCB, with the exception of a transient increase in CFDA-AM fluorescence in cells exposed in suspension (Fig. 2b). Being a highly lipophilic compound, it appears likely that HCB affects plasma and organelle membranes. However, literature is controversial about the impact of HCB on cellular membranes. Human embryonic fibroblasts (WS1) were reported to become hyperpermeable from one to three hours after treatment with 0.1 and $1 \mu \mathrm{g} \mathrm{L}^{-1} \mathrm{HCB}$, while mouse embryonic fibroblast cells (NIH 3T3) only showed membrane damage three hours after exposure to $1 \mu \mathrm{g} \mathrm{L}{ }^{-1} \mathrm{HCB}^{29}$ Conversely, a study conducted with the crustacean Squilla mantis found that HCB caused an increase in rigidity of plasma membranes of muscular and gonadic primary cells at a concentration of $14 \mu \mathrm{g} \mathrm{L}^{-1}{ }^{53}$ An increase in rigidity - which leads to a decrease in permeability - 

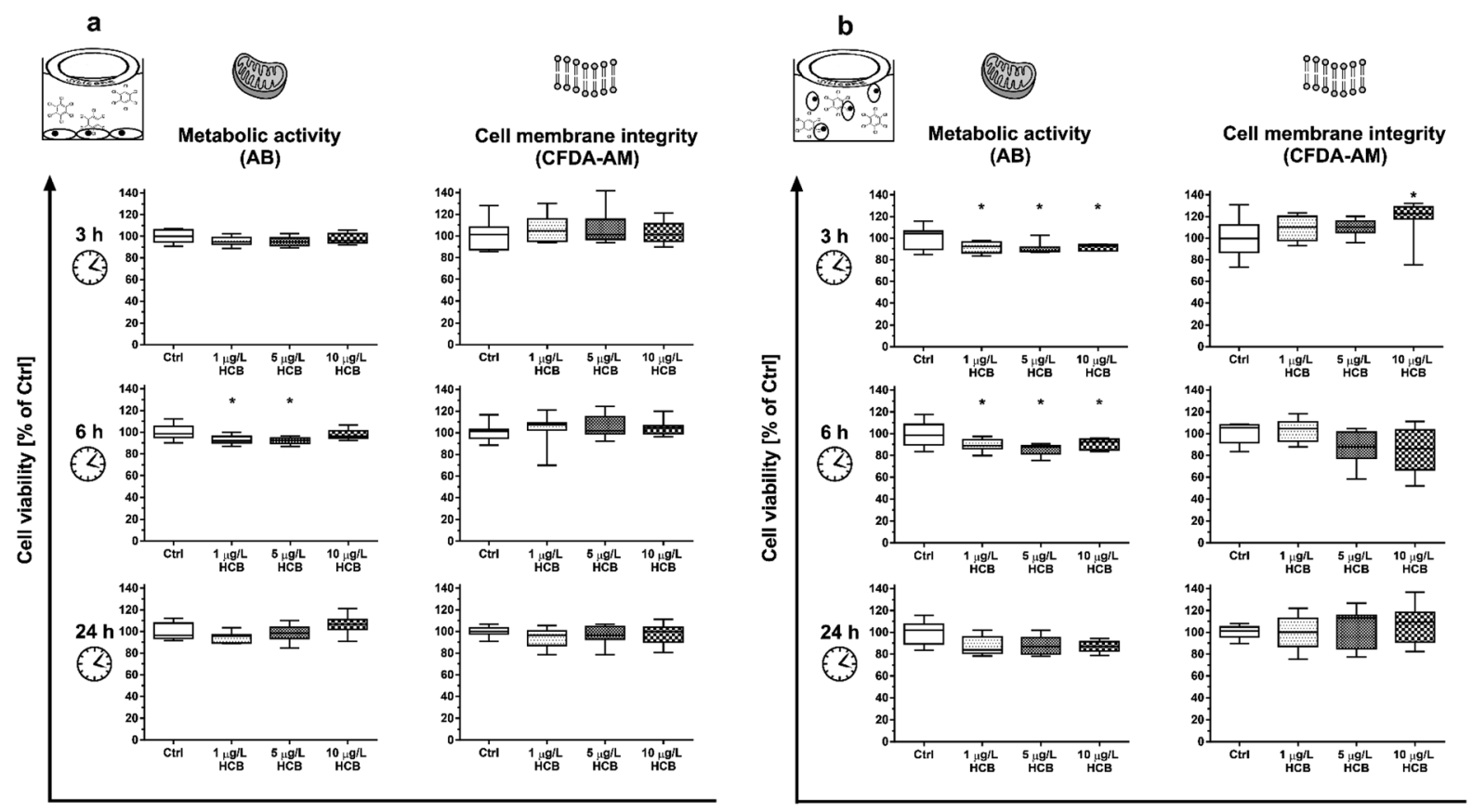

Fig. 2 Impact of HCB exposure on cell viability. (a) Impact of HCB on established monolayers. Attached monolayers of HuWaTERT were exposed to 1, 5, and $10 \mu \mathrm{g} \mathrm{L}^{-1} \mathrm{HCB}$ using the pre-equilibrated DMEM/F12 (1\% FBS) exposure medium and silicone O-rings for passive dosing. Metabolic activity and membrane integrity were assessed relative to control after 3,6 , and 24 hours. Plots represent the median, $1^{\text {st }}$ and $3^{\text {rd }}$ quartile, and whiskers the $5^{\text {th }}$ and $95^{\text {th }}$ percentile of three biological replicates. (b) Impact of HCB on cells during attachment. HuWa TERT cells in suspension were continuously exposed to 1,5 , and $10 \mu \mathrm{g} \mathrm{L}^{-1} \mathrm{HCB}$ using pre-equilibrated DMEM/F12 (1\% FBS) exposure medium with passive dosing during the phase of attachment to well bottoms. Metabolic activity and membrane integrity were assessed relative to control after 3, 6, and 24 hours. Plots represent the median, $1^{\text {st }}$ and $3^{\text {rd }}$ quartile, and whiskers the $5^{\text {th }}$ and $95^{\text {th }}$ percentile of three biological replicates.

may also be the cause for the transient increase in CFDA-AM fluorescence we observed. A potential explanation is described in a study conducted with the prokaryote Pseudomonas putida, where a cis-trans-isomerisation of membrane lipids was found to be the cause of an increase in rigidity following exposure to a concentration range of 0.01 to $1 \mu \mathrm{g} \mathrm{L}^{-1} \mathrm{HCB}^{54}$ Thus, the transient effect in CFDA-AM fluorescence in HuWa ${ }_{\text {TERT }}$ upon exposure to HCB may be attributed to the cells' sensitivity window immediately after seeding.

Overall, while sensitivity of cells to HCB appears to be tissue and species specific, ${ }^{55}$ HCB does not appear to exert strong acute toxicity at environmentally relevant concentrations in humpback whale cells. This is in line with the fact that HCB is not generally classified as an acutely toxic chemical. ${ }^{56}$

3.2.2. Genotoxic effects of HCB. HUWa $\mathrm{T}_{\mathrm{TERT}}$ cells exposed to $10 \mu \mathrm{g} \mathrm{L}{ }^{-1} \mathrm{HCB}$ for three hours during the sensitive phase of suspension and attachment were found to have significantly more DNA damage than control cells $(p<0.0001)$ (Fig. 3a and $\mathrm{S} 8 \dagger)$. In addition, the effect appeared to be concentrationdependent (Fig. 3b), but as this experiment was only carried out with one biological replicate no statistical analysis was performed to determine whether the concentration dependency is statistically significant. The observed effect is unlikely attributable to apoptosis; as the comet assay was carried out under the same conditions as the cytotoxicity assay, the results of the latter may be used as an interpretation aid to the former. In case of a reduction in cell numbers, i.e. apoptosis of some of the cells, both $\mathrm{AB}$ and CFDA-AM fluorescence should decrease, which we did not observe. In addition, if the reduction in fluorescence was a consequence of cell death, the effect would still be measurable after 24 hours. From this we can infer that HCB, under the conditions administered both in the cytotoxicity and comet assay, does not cause apoptosis.

The International Agency for Research on Cancer (IARC) classifies HCB as a possible carcinogen, but there is some debate as to whether it is genotoxic. A variety of genotoxicity studies has produced predominantly negative findings. ${ }^{17,57-61}$ However, there have also been some contradictory results. While one study reported negative results for chromosomal aberrations of HCB in human lymphocytes at concentrations of 2.8-22.8 $\mathrm{g} \mathrm{L}^{-1}$ and 44 hours exposure, ${ }^{62}$ a different study found that HCB caused both an increase in the frequency of micronuclei formation and of DNA breaks in primary human lymphocytes at concentrations of 30 to $160 \mathrm{mg} \mathrm{L}^{-1}$ and 20 hours exposure. ${ }^{30}$ The same study found that, using the same exposure conditions, there was also an increase in micronuclei formation in primary rat hepatocytes, but without concurrent increase in DNA breaks, indicating an aneugenic mechanism of action. The authors concluded that HCB is a weak genotoxic carcinogen. Using concentrations better comparable to ours, Salmon et al. $(2002)^{29}$ found that both mouse and human 
a

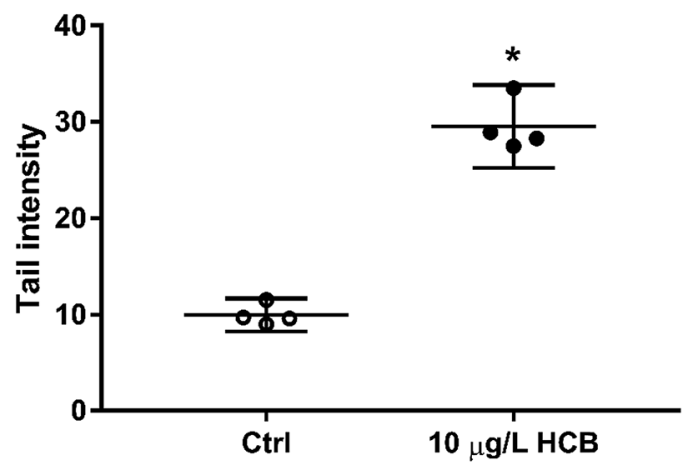

b

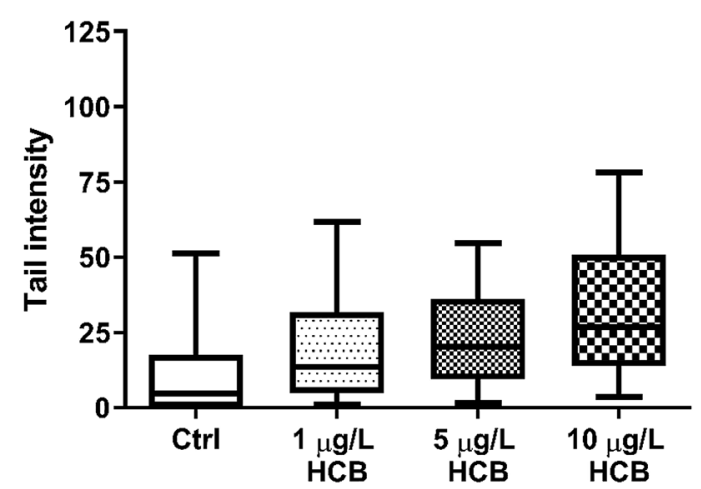

Fig. 3 Tail intensities of cells treated with HCB compared to HCB-free controls. (a) HCB-induced DNA damage. The comet assay was performed with HUWaTERT cells after exposure to $10 \mu \mathrm{g} \mathrm{L}^{-1} \mathrm{HCB}$ for three hours during the phase of attachment to well bottoms using pre-equilibrated DMEM/F12 (1\% FBS) exposure medium with passive dosing. Plots represent the mean and $95 \% \mathrm{Cl}$ of mean tail intensity of four biological replicates with 100 analysed cells each. (b) Apparent concentration dependency of HCB-induced DNA damage. The comet assay was performed after HuWaTERT cells were exposed to 1,5 , and $10 \mu \mathrm{g} \mathrm{L}^{-1} \mathrm{HCB}$ for three hours during the phase of attachment to well bottoms using preequilibrated DMEM/F12 ( $1 \%$ FBS) exposure medium with passive dosing. Plots represent the median, $1^{\text {st }}$ and $3^{\text {rd }}$ quartile, and whiskers the $5^{\text {th }}$ and $95^{\text {th }}$ percentile, of one biological replicate with 100 analysed cells each in the control and the HCB-treated groups.

embryonic fibroblasts showed a significant increase in DNA breaks following four hours of exposure to 0.1 and $1 \mu \mathrm{g} \mathrm{L^{-1 }}$ HCB. Finally, a significant increase in DNA breaks was also found in human colon carcinoma cells exposed to 0.1 and 114 $\mu \mathrm{g} \mathrm{L}{ }^{-1} \mathrm{HCB}$ for 14 days. $^{27}$

It is difficult to compare the results of different genotoxicity studies not only due to different species and endpoints assessed, but also due to the different exposure setups and vast differences in HCB concentrations applied. Nonetheless, there is previous evidence in the literature that $\mathrm{HCB}$ has the potential to cause DNA damage. Our results add to this body of evidence. In the absence of significant cytotoxic effects as seen in this study, the observed DNA fragmentation is unlikely to be a result of apoptotic processes of DNA disintegration, suggesting that HCB causes DNA single and/or double strand breaks at environmentally relevant concentrations in humpback whale fibroblasts. In the future, it would be interesting to investigate the apparent concentration dependence and time course of DNA damage, as well as to explore the underlying mechanism of action not only for DNA damage but as well the transient effects seen on cell viability.

Taken together, we established a ready-to-use passive dosing setup for exposure experiments with $\mathrm{HCB}$, providing all the necessary partitioning coefficients, and thus offering a stable system and controlled conditions applicable to a broad variety of in vitro assays. By applying the unique $\mathrm{HuWa}_{\mathrm{TERT}}$ cell line in this exposure set-up, we have shown that HCB has the potential to reduce cell viability, and to clearly cause DNA damage. These findings are of particular relevance for the toxicity assessment of HCB in humpback whales because highest organism-internal exposures occur when females are pregnant and nursing, thus coinciding with vulnerable developmental stages. Our combined passive dosing-HuWa $\mathrm{T}_{\mathrm{TERT}}$ system therefore offers a wealth of opportunities to study the action of Antarctic priority pollutants on humpback whale cells in a species-specific manner.

\section{Abbreviations}

$\begin{array}{ll}\text { AB } & \text { AlamarBlue } \\ \text { CFDA-AM } & \text { 5-Carboxyfluorescein diacetate acetoxymethylester } \\ \text { CI } & \text { Confidence interval } \\ \text { DMEM } & \text { Dulbecco's modified Eagle medium } \\ \text { FBS } & \text { Fetal bovine serum } \\ \text { HCB } & \text { Hexachlorobenzene } \\ \text { IARC } & \text { International Agency for Research on Cancer } \\ \text { LB } & \text { Loading buffer } \\ \text { PBS } & \text { Phosphate-buffered saline } \\ \text { POPs } & \text { Persistent organic pollutants } \\ \text { PTFE } & \text { Polytetrafluoroethylene } \\ \text { SD } & \text { Standard deviation } \\ \text { TERT } & \text { Telomerase reverse transcriptase } \\ \text { Caco-2 } & \text { Human colon adenocarcinoma cell line } \\ \text { CHL } & \text { Chinese hamster lung cell line } \\ \text { FRTL-5 } & \text { Rat thyroid cell line } \\ \text { HuWa } & \text { Humpback whale fibroblast cell line } \\ \text { NIH 3T3 } & \text { Mouse embryonic fibroblast cell line } \\ \text { WS1 } & \text { Human embryonic fibroblast cell line }\end{array}$

\section{Author contributions}

All authors contributed to the design of this study. JM and MB carried out the experiments and evaluated all the data, with the exception of the comet assay, which was analysed by JCC. The manuscript was written through contributions of all authors. All authors have given approval to the final version of the manuscript. 


\section{Funding sources}

This work was supported by Eawag internal funds. MB acknowledges initial support by a PhD scholarship from Griffith University. JCC acknowledges funding from the NanoScreen Materials Challenge co-funded by the Competence Centre for Materials Science and Technology (CCMX).

\section{Conflicts of interest}

There are no conflicts to declare.

\section{Acknowledgements}

We are grateful to René Schönenberger for support in chemical analysis, as well as Melanie Fischer and Nadine Bramaz for support in cell culture and cytotoxicity testing.

\section{References}

1 R. J. Letcher, J. O. Bustnes, R. Dietz, B. M. Jenssen, E. H. Jørgensen, C. Sonne, J. Verreault, M. M. Vijayan and G. W. Gabrielsen, Exposure and effects assessment of persistent organohalogen contaminants in arctic wildlife and fish, Sci. Total Environ., 2010, 408, 2995-3043.

2 R. Kallenborn, H. Hung and E. Brorström-Lundén, Atmospheric long-range transport of persistent organic pollutants (POPs) into polar regions, Compr. Anal. Chem., 2015, 67, 411-432.

3 A. L. Chiuchiolo, R. M. Dickhut, M. A. Cochran and H. W. Ducklow, Persistent organic pollutants at the base of the Antarctic marine food web, Environ. Sci. Technol., 2004, 38, 3551-3557.

4 S. M. Bengtson Nash, A. H. Poulsen, S. Kawaguchi, W. Vetter and M. Schlabach, Persistent organohalogen contaminant burdens in Antarctic krill (Euphausia superba) from the eastern Antarctic sector: a baseline study, Sci. Total Environ., 2008, 407, 304-314.

5 S. M. Bengtson Nash, S. J. Wild, D. W. Hawker, R. A. Cropp, H. Hung, F. Wania, H. Xiao, P. Bohlin-Nizzetto, A. Bignert and S. Broomhall, Persistent organic pollutants in the East Antarctic atmosphere: inter-annual observations from 2010 to 2015 using high-flow-through passive sampling, Environ. Sci. Technol., 2017, 51, 13929-13937.

6 S. M. Bengtson Nash, A. H. Poulsen, S. Kawaguchi and M. Schlabach, Hexachlorobenzene in a Southern Ocean food web; contaminant accumulation \& global comparisons, Organohalogen Compd., 2007, 69, 1685-1688.

7 R. Kallenborn, K. Breivik, S. Eckhardt, C. R. Lunder, S. Manø, M. Schlabach and A. Stohl, Long-term monitoring of persistent organic pollutants (POPs) at the Norwegian Troll station in Dronning Maud Land, Antarctica, Atmos. Chem. Phys., 2013, 13, 6983-6992.

8 S. M. Bengtson Nash, C. A. Waugh and M. Schlabach, Metabolic concentration of lipid soluble organochlorine burdens in the blubber of southern hemisphere humpback whales through migration and fasting, Environ. Sci. Technol., 2013, 47, 9404-9413.

9 P. R. Dorneles, J. Lailson-Brito, E. R. Secchi, A. C. Dirtu, L. Weijs, L. Dalla Rosa, M. Bassoi, H. A. Cunha, A. F. Azevedo and A. Covaci, Levels and profiles of chlorinated and brominated contaminants in Southern Hemisphere humpback whales, Megaptera novaeangliae, Environ. Res., 2015, 138, 49-57.

10 K. Das, G. Malarvannan, A. Dirtu, V. Dulau, M. Dumont, G. Lepoint, P. Mongin and A. Covaci, Linking pollutant exposure of humpback whales breeding in the Indian Ocean to their feeding habits and feeding areas off Antarctica, Environ. Pollut., 2017, 220, 1090-1099.

11 J. De Bruijn, F. Busser, W. Seinen and J. Hermens, Determination of octanol/water partition coefficients for hydrophobic organic chemicals with the "slow-stirring" method, Environ. Toxicol. Chem., 1989, 8, 499-512.

12 W. Y. Shiu, F. Wania, H. Hung and D. Mackay, Temperature dependence of aqueous solubility of selected chlorobenzenes, polychlorinated biphenyls, and dibenzofuran, J. Chem. Eng. Data, 1997, 42, 293-297.

13 J. L. Barber, A. J. Sweetman, D. Van Wijk and K. C. Jones, Hexachlorobenzene in the global environment: emissions, levels, distribution, trends and processes, Sci. Total Environ., 2005, 349, 1-44.

14 L. M. Jantunen and T. F. Bidleman, Henry's law constants for hexachlorobenzene, $\mathrm{p}, \mathrm{p}^{\prime}$-DDE and components of technical chlordane and estimates of gas exchange for Lake Ontario, Chemosphere, 2006, 62, 1689-1696.

15 ATSDR, Toxicological Profile for Hexachlorobenzene, Atlanta, GA, 2013, vol. 2013.

16 USEPA, Provisional Peer-Reviewed Toxicity Values for Hexachlorobenzene, Cincinnati, OH, 2010.

17 IARC, Hexachlorobenzene, IARC Monographs on the Evaluation of Carcinogenic Risk of Chemicals to Humans, 2001, vol. 79.

18 R. J. Jandacek, Effects of yo-yo diet, caloric restriction, and olestra on tissue distribution of hexachlorobenzene, Am. J. Physiol.: Gastrointest. Liver Physiol., 2005, 288, G292-G299.

19 J. Acevedo, K. Rasmussen, F. Félix, C. Castro, M. Llano, E. Secchi, M. T. Saborío, A. Aguayo-Lobo, B. Haase, M. Scheidat, L. Dalla-Rosa, C. Olavarría, P. Forestell, P. Acuña, G. Kaufman and L. A. Pastene, Migratory destinations of humpback whales from the Magellan Strait feeding ground, Southeast Pacific, Mar. Mammal Sci., 2007, 23, 453-463.

20 S. M. Bengtson Nash, et al., Report of the IWC Pollution 2000+ Phase II Workshop, J. Cetacean Res. Manage., 2011, 12(supp.), 421-436.

21 L. Weijs and A. Zaccaroni, Toxicology of marine mammals: new developments and opportunities, Arch. Environ. Contam. Toxicol., 2016, 70, 1-8.

22 B. J. Blaauboer, The long and winding road of progress in the use of in vitro data for risk assessment purposes: from 'carnation test' to integrated testing strategies, Toxicology, 2015, 332, 4-7. 
23 M. C. Fossi, L. Marsili, S. Casini and D. Bucalossi, Development of new-tools to investigate toxicological hazard due to endocrine disruptor organochlorines and emerging contaminants in Mediterranean cetaceans, Mar. Environ. Res., 2006, 62, 200-204.

24 J. M. Gauthier, H. Dubeau and E. Rassart, Induction of micronuclei in vitro by organochlorine compounds in beluga whale skin fibroblasts, Mutat. Res., Genet. Toxicol. Environ. Mutagen., 1999, 439, 87-95.

25 M. Burkard, D. Whitworth, K. Schirmer and S. M. Bengtson Nash, Establishment of the first humpback whale fibroblast cell lines and their application in chemical risk assessment, Aquat. Toxicol., 2015, 167, 240-247.

26 M. Burkard, S. Bengtson Nash, G. Gambaro, D. Whitworth and K. Schirmer, Lifetime extension of humpback whale skin fibroblasts and their response to lipopolysaccharide (LPS) and a mixture of polychlorinated biphenyls (Aroclor), Cell Biol. Toxicol., 2019, 35, 387-398.

27 H. Chalouati, E. Boutet, B. Metais, E. Fouche, M. M. Ben Sâad and L. Gamet-Payrastre, DNA damage and oxidative stress induced at low doses by the fungicide hexachlorobenzene in human intestinal Caco-2 cells, Toxicol. Mech. Methods, 2015, 25, 448-458.

28 F. Chiappini, C. Pontillo, A. S. Randi, L. Alvarez and D. L. K. De Pisarev, Reactive oxygen species and extracellular signal-regulated kinase $1 / 2$ mediate hexachlorobenzene-induced cell death in frtl-5 rat thyroid cells, Toxicol. Sci., 2013, 134, 276-290.

29 M. L. Salmon, S. G. Madanagopal, R. Blando, J. Berner and K. Williams, Effects of hexachlorobenzene on embryonic mammalian cells, Toxicol. In Vitro, 2002, 16, 539-548.

30 R. Canonero, G. B. Campart, F. Mattioli, L. Robbiano and A. Martelli, Testing of p-dichlorobenzene and hexachlorobenzene for their ability to induce DNA damage and micronucleus formation in primary cultures of rat and human hepatocytes, Mutagenesis, 1997, 12, 35-39.

31 R. Schreiber, R. Altenburger, A. Paschke and E. Küster, How to deal with lipophilic and volatile organic substances in microtiter plate assays, Environ. Toxicol. Chem., 2008, 27, 1676.

32 K. Tanneberger, A. Rico-Rico, N. I. Kramer, F. J. M. Busser, J. L. M. Hermens and K. Schirmer, Effects of solvents and dosing procedure on chemical toxicity in cell-based in vitro assays, Environ. Sci. Technol., 2010, 44, 4775-4781.

33 N. I. Kramer, F. J. M. Busser, M. T. T. Oosterwijk, K. Schirmer, B. I. Escher and J. L. M. Hermens, Development of a partition-controlled dosing system for cell assays, Chem. Res. Toxicol., 2010, 23, 1806-1814.

34 K. E. C. Smith, G. J. Oostingh and P. Mayer, Passive dosing for defined \& constant exposure of hydrophobic organic compounds during in Vitro toxicity tests, Chem. Res. Toxicol., 2010, 23, 55-65.

35 K. E. C. Smith, N. Dom, R. Blust and P. Mayer, Controlling and maintaining exposure of hydrophobic organic compounds in aquatic toxicity tests by passive dosing, Aquat. Toxicol., 2010, 98, 15-24.
36 K. E. C. Smith, M. B. Heringa, M. Uytewaal and P. Mayer, The dosing determines mutagenicity of hydrophobic compounds in the Ames II assay with metabolic transformation: passive dosing versus solvent spiking, Mutat. Res., Genet. Toxicol. Environ. Mutagen., 2013, 750, 12-18.

37 T. B. Seiler, N. Best, M. M. Fernqvist, H. Hercht, K. E. C. Smith, T. Braunbeck, P. Mayer and H. Hollert, $\mathrm{PAH}$ toxicity at aqueous solubility in the fish embryo test with Danio rerio using passive dosing, Chemosphere, 2014, 112, 77-84.

38 G. J. Oostingh, K. E. C. Smith, U. Tischler, I. Radauer-Preiml and P. Mayer, Differential immunomodulatory responses to nine polycyclic aromatic hydrocarbons applied by passive dosing, Toxicol. In Vitro, 2015, 29, 345-351.

39 D. Gilbert, P. Mayer, M. Pedersen and A. M. Vinggaard, Endocrine activity of persistent organic pollutants accumulated in human silicone implants - Dosing in vitro assays by partitioning from silicone, Environ. Int., 2015, 84, 107-114.

40 F. Fischer, L. Böhm, S. Höss, C. Möhlenkamp, E. Claus, R.-A. Düring and S. Schäfer, Passive dosing in chronic toxicity tests with the Nematode Caenorhabditis elegans, Environ. Sci. Technol., 2016, 50, 9708-9716.

41 H. Schug, F. Begnaud, C. Debonneville, F. Berthaud, S. Gimeno and K. Schirmer, TransFEr: a new device to measure the transfer of volatile and hydrophobic organic chemicals across an in vitro intestinal fish cell barrier, Anal. Methods, 2018, 10, 4394-4403.

42 J. E. Yordy, R. S. Wells, B. C. Balmer, L. H. Schwacke, T. K. Rowles and J. R. Kucklick, Partitioning of persistent organic pollutants between blubber and blood of wild bottlenose dolphins: implications for biomonitoring and health, Environ. Sci. Technol., 2010, 44, 4789-4795.

43 R. Cropp, S. M. Bengtson Nash and D. Hawker, A model to resolve organochlorine pharmacokinetics in migrating humpback whales, Environ. Toxicol. Chem., 2014, 33, 16381649.

44 K. Schirmer, A. G. J. Chan, B. M. Greenberg, D. G. Dixon and N. C. Bols, Methodology for demonstrating and measuring the photocytotoxicity of fluoranthene to fish cells in culture, Toxicol. In Vitro, 1997, 11, 107-119.

45 J. O'Brien, I. Wilson, T. Orton and F. Pognan, Investigation of the Alamar Blue (resazurin) fluorescent dye for the assessment of mammalian cell cytotoxicity, Eur. J. Biochem., 2000, 267, 5421-5426.

46 R. C. Ganassin, K. Schirmer and N. C. Bols, in The Laboratory Fish, Elsevier, 2000, pp. 631-651.

47 V. R. Dayeh, N. C. Bols, K. Schirmer and L. E. J. Lee, The use of fish-derived cell lines for investigation of environmental contaminants, Curr. Protoc. Toxicol., 2004, 15, 1.5.1-1.5.17.

48 P. L. Olive and J. P. Banáth, The comet assay: a method to measure DNA damage in individual cells, Nat. Protoc., 2006, 1, 23-29.

49 D. P. Lovell and T. Omori, Statistical issues in the use of the comet assay, Mutagenesis, 2008, 23, 171-182. 
50 P. Mayer, J. Wernsing, J. Tolls, P. G. J. De Maagd and D. T. H. M. Sijm, Establishing and controlling dissolved concentrations of hydrophobic organics by partitioning from a solid phase, Environ. Sci. Technol., 1999, 33, 22842290.

51 M. M. Becker and W. Gamble, Determination of the binding of $2,4,5,2^{\prime}, 4^{\prime}, 5^{\prime}$-hexachlorobiphenyl by low density lipoprotein and bovine serum albumin, J. Toxicol. Environ. Health, 1982, 9, 225-234.

52 N. A. Dorfman, C. I. Civin and J. R. Wunderlich, Susceptibility of adherent versus suspension target cells derived from adherent tissue culture lines to cell-mediated cytotoxicity in rapid ${ }^{51}$ Cr-release assays, J. Immunol. Methods, 1980, 32, 127-139.

53 A. Dell'Anno, F. Raffaelli, R. Danovaro, L. Nanetti, A. Vignini, C. Moroni and L. Mazzanti, Cytotoxic effects induced by hexachlorobenzene in Squilla mantis (L.) (Crustacea, Stomatopoda), Environ. Toxicol., 2008, 23, 9-14.

54 M. Vodovnik, M. Bistan, M. Zorec and R. M. Logar, Membrane changes associated with exposure of pseudomonas putida to selected environmental pollutants and their possible roles in toxicity, Acta Chim. Slov., 2012, 59, 83-88.

55 A. Delisle, E. Ferraris and I. Plante, Chronic exposure to hexachlorobenzene results in down-regulation of connexin43 in the breast, Environ. Res., 2015, 143, 229-240.
56 B. Starek-Świechowicz, B. Budziszewska and A. Starek, Hexachlorobenzene as a persistent organic pollutant: toxicity and molecular mechanism of action, Pharmacol. Rep., 2017, 69, 1232-1239.

57 S. Haworth, T. Lawlor, K. Mortelmans, W. Speck and E. Zeiger, Salmonella mutagenicity test results for 250 chemicals, Environ. Mutagen., 1983, 5(suppl. 1), 1-142.

58 T. Górski, E. Górska, D. Górecka and M. Sikora, Hexachlorobenzene is non-genotoxic in short-term tests, IARC Sci. Publ., 1986, 77, 399-401.

59 P. Siekel, I. Chalupa, J. Beno, M. Blasko, J. Novotný and J. Burian, A genotoxicological study of hexachlorobenzene and pentachloroanisole, Teratog. Carcinog. Mutagen., 1991, 11, 55-60.

60 D. J. Brusick, Genotoxicity of hexachlorobenzene and other chlorinated benzenes, IARC Sci. Publ., 1986, 77, 393-397.

61 M. Ishidate, Data book of chromosomal aberration test in vitro, Elsevier Science \& Technology, Oxford UK, 2nd revise, 1988.

62 S. Ennaceur, D. Ridha and R. Marcos, Genotoxicity of the organochlorine pesticides 1,1-dichloro-2,2-bis(pchlorophenyl)ethylene (DDE) and hexachlorobenzene (HCB) in cultured human lymphocytes, Chemosphere, 2008, 71, 1335-1339. 